Piotr LiZAK

Akademia Pedagogiczna, Kraków

\title{
Wpływ koncernu Fiat na ksztaltowanie się przemysłu samochodów osobowych w Polsce
}

W wyniku zmiany systemu gospodarowania i otwarcia gospodarki krajowej na otoczenie międzynarodowe powstały w Polsce korzystne warunki dla napływu bezpośrednich inwestycji zagranicznych (BIZ) rożnego rodzaju firm. Wraz z wejściem w życie ustawy z dnia 14 czerwca 1991 o spółkach z udziałem kapitału zagranicznego rozpoczął się stały dopływ do Polski bezpośrednich inwestycji zagranicznych (Piasecka 2001). Nasilenie tego zjawiska związane jest ściśle z działaniami na rzecz podniesienia pozycji konkurencyjnej krajowych regionów.

Przedmiotem w niniejszej pracy będzie analiza wpływu koncernu Fiat na rozwój przemysłu samochodów osobowych w Polsce. O znaczeniu koncernu Fiat wśród wiodących światowych korporacji świadczy fakt, iż korporację tę charakteryzuje ogólna wartość sprzedaży w 2005 r. na poziomie 63,08 mld USD, ogólna wartość majątku 75,72 mld USD oraz całkowita wartość rynkowa wynosząca 13,81 mld USD, co daje jej 548 pozycję wśród wszystkich korporacji, podczas gdy największe firmy samochodowe świata znajdują się na czele listy światowych największych korporacji, np. Toyota Motor zajmuje 12 pozycję, Honda Motor 63 pozycję, Ford Motor 133 pozycję. (Forbes 2006).

Do 1989 roku działalność międzynarodowych koncernów motoryzacyjnych w Polsce ograniczała się do sprzedaży licencji, dzięki czemu podejmowano krajową produkcję samochodów w FSO i FSM. Zmiana systemu gospodarowania i związane z tym urynkowienie gospodarki oraz otwarcie jej na otoczenie międzynarodowe miało wpływ na zmiany w przemyśle całej Polski, w tym także w funkcjonowaniu polskiego przemysłu motoryzacyjnego.

We współczesnym świecie korporacje międzynarodowe, w tym koncerny motoryzacyjne, są nośnikiem największej siły rozwoju w światowej gospodarce, także w dziedzinie motoryzacji. Są pionierami głównie w dziedzinie badań naukowych (koncern Honda przeznacza na rozwój nowych technologii rocznie ok. 5,4 mld USD) i w sferze wdrażania nowych technologii. Wpływ koncernu Fiat na kształt krajowego przemysłu samochodów osobowych przejawia się podniesieniem atrakcyjności i dbałości o konkurencyjność produkcji poprzez ogólną sumę zainwestowanego kapitału przez koncern w Polsce, która w latach 1992-2003 wyniosła 1,87 mld USD.

W latach 90. w Polsce pojawiły się również inne międzynarodowe koncerny motoryzacyjne. Dysponowały wieloma atutami, które sprawiały, iż ich produkty były znacznie bardziej konkurencyjne niż produkty wytwarzane do tej pory w kraju. Do ich najważniejszych atutów zaliczyć należy: atrakcyjne produkty - samochody znacznie przewyższające jakością 
samochody do tej pory produkowane w kraju, wprowadzenie nowych konstrukcji, dostępność do znacznych zasobów kapitału, silny marketing; doskonałą kadrę zarządzającą posiadającą doświadczenie w zarządzaniu zakładem w warunkach gospodarki rynkowej (Kamiński 2005). Nadto należy dodać niższe koszty pracy oraz wykształcone kadry pracownicze.

Obecnie polski przemysł samochodów osobowych w największym stopniu związany jest z włoskim koncernem motoryzacyjnym Fiat. Koncern ten jest obecny w Polsce już od 1932 r., kiedy to podpisano pierwszą umowę licencyjną pomiędzy polskim rządem a Fiatem, obejmującą budowę fabryki samochodów osobowych w Warszawie przy ulicy Terespolskiej. W nawiązaniu do wcześniejszych tradycji i powiązań gospodarczych w 1967 r. włoski koncern uruchomił produkcję samochodów Fiat $125 \mathrm{w}$ Warszawskiej Fabryce Samochodów Osobowych (FSO) na Żeraniu, zastępując w ten sposób produkowane do tej pory samochody Warszawa i Syrena. W 1971 r. Fiat uruchomił w Bielsku-Białej i Tychach nowoczesną Fabrykę Samochodów Małolitrażowych (FSM). W latach 80. wraz z uruchomieniem procesów transformacji gospodarki znacznie pogorszyły się warunki rozwoju przemysłu samochodowego, w wyniku czego nastapiła stopniowa recesja całej gospodarki, w tym także polskiego przemysłu samochodowego. Było to wynikiem braku środków finansowych całego sektora, spowodowanym przechwytywaniem przez budżet państwa akumulacji przemysłu samochodowego. W konsekwencji producenci nie mieli możliwości nie tylko unowocześnienia produkcji, ale nawet odtworzenia majątku, co w połączeniu z ,pętlą kredytową" i rygorystyczną polityką fiskalną państwa doprowadziło branżę samochodową do upadku (Menes E. 1998).

W latach 90., w okresie wdrażania reguł gospodarki rynkowej oraz związanych z nią instrumentów prawnych, uruchomiono napływ bezpośrednich inwestycji zagranicznych, w tym inwestycji do przemysłu samochodów osobowych. W pierwszej połowie lat 90 . inwestycje zagraniczne polegały w głównej mierze na przejęciu, a następnie przekształceniu i modernizowaniu firm już istniejących. W drugiej połowie lat 90. inwestycje zagraniczne ukierunkowane były na budowę od podstaw nowoczesnych zakładów.

W październiku 1992 r. koncern Fiat przejął posiadającą poważne problemy finansowe Fabrykę Samochodów Małolitrażowych (FSM) w Tychach i Bielsku-Białej. Włoski koncern współpracował z FSM już od ponad 20 lat, a fabryka produkowała samochody na licencjach zakupionych wcześniej od Fiata. Po przejęciu FSM koncern Fiat wprowadził na jej miejsce trzy nowe firmy należące do Grupy Fiata. Powstały wówczas: Fiat Auto Poland zajmująca się produkcją samochodów (Bielsko-Biała i Tychy) oraz wytwarzaniem linek i cięgien w zakładzie w Częstochowie, Teksid Poland zajmująca się wykonywaniem wszelkich specjalistycznych odlewów dla przemysłu motoryzacyjnego (Skoczów, Bielsko-Biała) oraz Magneti-Marelli zajmująca się produkcją zestawów wskaźników i elementów oświetlenia (Sosnowiec) oraz układów wydechowych (Dąbrowa Górnicza). Poza zakładami w BielskuBiałej, Tychach, Sosnowcu i Dąbrowie Górniczej Fiat przejął wiele mniejszych głównie państwowych firm, które wcześniej produkowały w ramach powiązań korporacyjnych wyroby na potrzeby FSM, a także zakłady produkujące inne wyroby niezwiązane z produkcją samochodów, np. Fabrykę Rowerów Apollo w Czechowicach-Dziedzicach i Bielską Fabrykę Obrabiarek.

Restrukturyzacja w zakładach Fiat Auto Poland (FAP) polegała na próbie sprzedaży zakładów niezwiązanych bezpośrednio z produkcja samochodów, a także na zakrojonej na dużą skalę akcji szkolenia pracowników dostosowującą zakład do podjęcia nowej produkcji i wdrożenia standardów obowiązujących w pozostałych zakładach koncernu. Przeszkolono 
łącznie około 3,5 tys. osób, a efektem tych działań było znaczne podniesienie jakości produkcji samochodów i komponentów samochodowych, czego dowodem było otrzymanie w 1996 r. certyfikatu ISO 9001, potwierdzającego najwyższy poziom gwarancji jakościowych we wszystkich dziedzinach zarządzania przedsiębiorstwem. Polskie zakłady Fiata otrzymały ten certyfikat jako pierwsze z wszystkich zakładów koncernu Fiat. W 2000 r. koncern Fiat podjął decyzje o zaprzestaniu montażu samochodów w zakładach w Bielsku-Białej, pozostawiając tam tylko produkcję skrzyni biegów i silników samochodowych.

Rozpoczynając restrukturyzację w dawnych zakładach FSM koncern Fiat sprzedawał zakłady niezwiązane bezpośrednio z produkcją samochodów, co skutkowało także sprzedażą zakładów produkujących części zamienne (tab. 1). W 1993 r. FAP sprzedał włoskiemu inwestorowi firmie Gestind zakład produkujący komponenty zlokalizowany w Bielsku Białej. Firma Gestind stając się właścicielem zakładu dokonała znacznej specjalizacji, koncentrując się na produkcji zagłówków, kierownic i gałek drążków zmiany biegów. W 2005 r. koncern Gestind zatrudniał 250 osób. Wyroby zakładu trafiają w znacznej mierze do zakładów FAP. Podobnie w 1994 r. koncern Fiat sprzedał włoskim firmom C.F. Gomma i Sila częstochowskie zakłady produkujące linki motoryzacyjne.

W ramach działań restrukturyzacyjnych sprywatyzowane zostały zakłady Fiata (dawnej FSM), byłe zakłady produkujące wyroby metalurgiczne na potrzeby motoryzacji w BielskuBiałej i Skoczowie. W 1992 r. przejęła je firma Teksid należąca do koncernu Fiat. Po przejęciu odlewni w Skoczowie postanowiono zaprzestać produkcji niezwiązanej z motoryzacją, a całą produkcję ukierunkować na wytwarzanie nowych komponentów samochodowych.

W 2001 r. koncern Fiat postanowił podzielić firmę Teksid Poland na 2 niezależne zakłady: Teksid Iron Poland, w skład którego weszła odlewnia żeliwa w Skoczowie, i Teksid Aluminium w skład którego weszła bielska odlewnia aluminium. W 2002 r. grupa Teksid Aluminium została sprzedana amerykańskiemu inwestorowi niezwiązanemu z motoryzacją. Obecnie roczna produkcja zakładu Teksid Iron Poland wynosi ok. 50000 ton odlewów żeliwa. W 2005 r. zakłady Teksid Iron Poland (nadal należące do koncernu Fiat) zatrudniały 517 pracowników.

Magneti-Marelli, należąca do grupy Fiat, w 1992 r. przejęła od Fiata Państwowy Zakład Konstrukcji Elektrycznych w Sosnowcu, przemianowując go na Automotive Lighting Polska. Prowadzi też inwestycje w dawnych Zakładach komponentów samochodowych FSM w Bielsku-Białej i Tychach (obecnie Magneti-Marelli Suspension Systems Poland), a także zakładach produkujących układy wydechowe w Dąbrowie Górniczej (obecnie Magneti-Marelli Exhaust Systems Polska).

W 2000 r. koncern Fiat zawiązał z amerykańskim koncernem motoryzacyjnym GM spółkę jonit-venture Fiat-GM Powertrain. Każdy z koncernów posiada po 50\% akcji spółki. Zakład ten zajmuje się projektowaniem i produkcją silników samochodowych oraz skrzyń biegów. Od 2000 r. zakład opuściło 5 mln sztuk zespołów napędowych oraz ponad $1 \mathrm{mln}$ silników diesla, przeznaczonych głównie dla zakładów Fiata i GM w Polsce i zagranica. W 2006 r. produkcja zakładu przeznaczona była w znacznej mierze na eksport, głównie do zakładów Fiata i GM. W 2005 r. zakład zatrudniał 1356 osób.

Koncern Fiat wywarł bardzo duży wpływ na kształt polskiego przemysłu motoryzacyjnego. W pierwszych latach transformacji gospodarki po przejęciu FSM sprzedał zakłady niezwiązane z produkcją samochodów, a w pozostałych fabrykach wdrożył programy naprawcze znacznie poprawiające organizacje pracy i stopień wyposażenia technicznego, 
co przyczyniło się do podniesienia wydajności pracy i jakości produkcji. Restrukturyzacja doprowadziła do specjalizacji produkcji w poszczególnych zakładach.

Tab. 1. Zmiany struktury organizacyjnej i profilu produkcji wybranych zakładów należących do FSM

\begin{tabular}{|c|c|c|c|c|}
\hline \multirow{2}{*}{ Dawna nazwa zakładu } & \multirow{2}{*}{$\begin{array}{l}\text { Przejmujący } \\
\text { inwestor }\end{array}$} & \multirow{2}{*}{$\begin{array}{c}\text { Obecna } \\
\text { nazwa zakładu }\end{array}$} & \multicolumn{2}{|c|}{ Zmiana profilu produkcji } \\
\hline & & & Dawny & Obecny \\
\hline $\begin{array}{l}\text { Fabryka Samochodów } \\
\text { Małolitrażowych }\end{array}$ & Fiat & Fiat Auto Poland & $\begin{array}{l}\text { produkcja } \\
\text { samochodów }\end{array}$ & $\begin{array}{l}\text { produkcja } \\
\text { samochodów }\end{array}$ \\
\hline $\begin{array}{l}\text { Fabryka Samochodów } \\
\text { Małolitrażowych } \\
\text { w Bielsku-Białej } \\
\text { Wapiennicy }\end{array}$ & Gestind & $\begin{array}{l}\text { Gestind } \\
\text { Wapiennica }\end{array}$ & $\begin{array}{l}\text { zagłówki, } \\
\text { podłokietniki } \\
\text { do foteli } \\
\text { samochodowych }\end{array}$ & $\begin{array}{l}\text { kołpaki } \\
\text { kierownice } \\
\text { drążki } \\
\text { zmiany biegów }\end{array}$ \\
\hline $\begin{array}{l}\text { Fabryka Samochodów } \\
\text { Małolitrażowych } \\
\text { Częstochowa }\end{array}$ & $\begin{array}{l}\text { C.F Gomma } \\
\text { i Sila }\end{array}$ & $\begin{array}{l}\text { C.F Gomma } \\
\text { Częstochowa } \\
\text { Sila Częstochowa }\end{array}$ & $\begin{array}{l}\text { linki } \\
\text { i cięgna } \\
\text { motoryzacyjne }\end{array}$ & $\begin{array}{l}\text { linki } \\
\text { i cięgna } \\
\text { motoryzacyjne }\end{array}$ \\
\hline $\begin{array}{l}\text { Odlewnie wchodzące } \\
\text { w skład FSM }\end{array}$ & $\begin{array}{l}\text { Teksid } \\
\text { (Grupa Fiat) }\end{array}$ & Teksid Iron Poland & $\begin{array}{l}\text { odlewy żeliwa } \\
\text { i aluminium } \\
\text { związane } \\
\text { z produkcją } \\
\text { samochodów, } \\
\text { a także poboczna } \\
\text { działalność } \\
\text { wytwórcza }\end{array}$ & $\begin{array}{l}\text { odlewy żeliwna } \\
\text { na potrzeby } \\
\text { motoryzacji }\end{array}$ \\
\hline $\begin{array}{l}\text { Zakłady Rowerowe } \\
\text { „Apollo" (wcześniej } \\
\text { zakład nr } 8 \text { FSM) } \\
\text { Czechowice Dziedzice }\end{array}$ & TRW & $\begin{array}{l}\text { TRW Steering } \\
\text { Systems Poland } \\
\text { Sp.z o.o. }\end{array}$ & rowery & $\begin{array}{l}\text { przekładnie } \\
\text { kierownicze }\end{array}$ \\
\hline Zakład Mechaniki FSM & Fiat-GM & $\begin{array}{l}\text { Fiat-GM } \\
\text { Powertrain }\end{array}$ & $\begin{array}{l}\text { silniki, zespoły } \\
\text { napędowe }\end{array}$ & $\begin{array}{l}\text { silniki, } \\
\text { skrzynie } \\
\text { biegów }\end{array}$ \\
\hline $\begin{array}{l}\text { Zakład Komponentów } \\
\text { Samochodowych FSM } \\
\text { Dąbrowa Górnicza }\end{array}$ & $\begin{array}{l}\text { Magnetti Marelli } \\
\text { (Grupa Fiat) }\end{array}$ & $\begin{array}{l}\text { Magneti-Marelli } \\
\text { Exhaust Systems } \\
\text { Polska }\end{array}$ & $\begin{array}{l}\text { plastikowe } \\
\text { komponenty } \\
\text { samochodowe }\end{array}$ & $\begin{array}{l}\text { układy } \\
\text { wydechowe }\end{array}$ \\
\hline $\begin{array}{l}\text { Zakład Komponentów } \\
\text { Samochodowych FSM } \\
\text { w Tychach }\end{array}$ & $\begin{array}{l}\text { Magnetti Marelli } \\
\text { (Grupa Fiat) }\end{array}$ & $\begin{array}{l}\text { Magnetti-Marelli } \\
\text { Suspensions } \\
\text { Systems Poland }\end{array}$ & $\begin{array}{l}\text { komponenty } \\
\text { samochodowe }\end{array}$ & zawieszenia \\
\hline $\begin{array}{l}\text { Państwowy Zakład } \\
\text { Konstrukcji } \\
\text { Elektrycznych } \\
\text { w Sosnowcu }\end{array}$ & $\begin{array}{l}\text { Magnetti Marelli } \\
\text { (Grupa Fiat) }\end{array}$ & $\begin{array}{l}\text { Automotive } \\
\text { Lighting Polska }\end{array}$ & $\begin{array}{l}\text { oświetlenie sa- } \\
\text { mochodowe }\end{array}$ & $\begin{array}{l}\text { oświetlenie } \\
\text { samochodowe }\end{array}$ \\
\hline
\end{tabular}


Obecnie w Polsce Grupę Fiat tworzy 17 spółek i trzy spółki joint-ventures (tab. 2). W strukturze zakładów najpoważniejsze znaczenie odgrywa zakład Fiat Auto Poland, zajmujący się produkcją samochodów, zatrudniający 3531 osób, tj. 40,1\% ogólnego zatrudnienia grupy. Kolejne miejsce zajmuje Fiat-GM Powertrain Polska zatrudniający 1356 pracowników, tj. 15,4\%. Oba zakłady odgrywają dominującą rolę i skupiają 55,5\% ogólnego zatrudnienia. Mniejsze znaczenie odgrywają zakłady Case New Holand i Automotive Lighting Poland zatrudniające po 758 pracowników, tj. po 8,6\%. W 2005 r. koncern Fiat zatrudniał w 17 zakładach łącznie 8812 pracowników.

Tab. 2. Struktura przestrzenna polskich firm należących do koncernu Fiat w 2005 r.

\begin{tabular}{|c|c|c|c|c|}
\hline Nazwa & Miejscowość & Specjalizacja produkcji & Zatrudnienie & $\begin{array}{c}\text { Struktura } \\
\text { zatrudnienia } \\
\text { w grupie FIAT } \\
(\mathrm{w} \%)\end{array}$ \\
\hline Fiat Auto Poland SA & Bielsko-Biała & $\begin{array}{c}\text { produkcja samochodów } \\
\text { osobowych }\end{array}$ & 3531 & 40,07 \\
\hline $\begin{array}{l}\text { Fiat-GM Powertrain } \\
\text { Polska Sp. z.o.o. }\end{array}$ & Bielsko-Biała & produkcja silników diesla & 1356 & 15,39 \\
\hline CNH Polska Sp. z.o.o. & Płock & $\begin{array}{c}\text { produkcja maszyn rolniczych } \\
\text { (gł. kombajnów) }\end{array}$ & 758 & 8,6 \\
\hline $\begin{array}{l}\text { Automotive Lighting } \\
\text { Polska Sp. z.o.o. }\end{array}$ & Sosnowiec & oświetlenie samochodowe & 758 & 8,6 \\
\hline $\begin{array}{l}\text { Business Solutions } \\
\text { Polska Sp. z.o.o }\end{array}$ & Bielsko-Biała & usługi księgowe & 675 & 7,66 \\
\hline $\begin{array}{l}\text { Teksid Iron Poland } \\
\text { Sp. z.o.o. }\end{array}$ & Skoczów & odlewy żeliwne & 517 & 5,87 \\
\hline $\begin{array}{c}\text { Magneti-Marelli } \\
\text { Suspension Systems } \\
\text { Poland } \\
\text { Sp. z.o.o. } \\
\end{array}$ & Sosnowiec & zawieszenia & 330 & 3,74 \\
\hline $\begin{array}{l}\text { Comau Poland } \\
\text { sp. z.o.o. }\end{array}$ & Tychy & $\begin{array}{c}\text { środki i systemy produkcji } \\
\text { dla fabryk fiata }\end{array}$ & 303 & 3,44 \\
\hline $\begin{array}{l}\text { Sirio Polska } \\
\text { Sp.z.o.o. }\end{array}$ & Bielsko-Biała & $\begin{array}{l}\text { agencja ochroniarska, } \\
\text { ochrona zakładów }\end{array}$ & 200 & 2,27 \\
\hline $\begin{array}{l}\text { Magneti Marelli } \\
\text { Exhaust systems Pol- } \\
\text { ska Sp.z.o.o. }\end{array}$ & Sosnowiec & układy wydechowe & 113 & 1,28 \\
\hline $\begin{array}{l}\text { Fiat Purchasing Polska } \\
\text { Sp. z.o.o }\end{array}$ & Bielsko-Biała & $\begin{array}{l}\text { zakup materiałów pośrednich } \\
\text { i bezpośrednich do produkcji } \\
\text { samochodów }\end{array}$ & 73 & 0,83 \\
\hline
\end{tabular}




\begin{tabular}{|c|c|c|c|c|}
\hline Fiat Bank Polska SA & Warszawa & $\begin{array}{c}\text { usługi finansowe, kredyty } \\
\text { samochodowe }\end{array}$ & 65 & 0,74 \\
\hline $\begin{array}{c}\text { Sadi-Polska - Agencja } \\
\text { Celna Sp. z.o.o }\end{array}$ & Bielsko-Biała & obsługa odpraw celnych & 44 & 0,5 \\
\hline $\begin{array}{c}\text { Ingest Facility Polska } \\
\text { Sp. z.o.o. }\end{array}$ & Bielsko-Biała & $\begin{array}{c}\text { zarządzanie nieruchomościami } \\
\text { Fiat Auto Poland }\end{array}$ & 41 & 0,47 \\
\hline $\begin{array}{c}\text { Iveco Poland Sp. z.o.o. } \\
\text { Fidis Finance Polska } \\
\text { Sp. z.o.o }\end{array}$ & Warszawa & $\begin{array}{c}\text { import i sprzedaż samochodów } \\
\text { użytkowych }\end{array}$ & 23 & 0,26 \\
\hline $\begin{array}{c}\text { udzielanie wsparcia } \\
\text { flinansowego }\end{array}$ & 13 & 0,15 \\
\hline $\begin{array}{c}\text { Fidis Leasing Polska } \\
\text { Sp. z.o.o. }\end{array}$ & Warszawa & usługi finansowe & 12 & 0,14 \\
\hline SUMA & & 8812 & $100 \%$ \\
\hline
\end{tabular}

Jak podkreśla Parysek i Stryjakiewicz (2000), w polskim przemyśle motoryzacyjnym nastąpiła dywersyfikacja rynku. W wyniku tzw. efektu ciagnienia powstała w Polsce sieć firm współpracujących z fabrykami samochodów i producentami podzespołów i części zamiennych dla tychże fabryk. Efekt ciągnienia polega na napływie inwestycji wspierających i okalających pierwotną inwestycję, w sektorze motoryzacyjnym objawia się poprzez napływ do strefy w bezpośrednim sąsiedztwie dużej fabryki produkującej samochody wielu firm kooperantów.

Fabryka Fiata w Bielsku-Białej przyciagnęła w ten sposób do Polski około 32 zagraniczne firmy z nią współpracujące, m.in. Teksid Aluminium (odlewnie aluminium), Teksid Iron Poland (odlewnie cynku i żelaza), Magneti Marelli; Gestind Manifactura di Bruzolo fabryka układów kierowniczych i skrzyni biegów w Bielsku-Białej Wapiennicy oraz Delphi produkującą kolumny kierownicze, TRW produkujące układy hamulcowe i inne.

W rezultacie efektu ciagnienia powstały w Polsce cztery obszary skupiające firmy z branży motoryzacyjnej. Obszary te to: Bielsko Biała-Gliwice związane z fabrykami Fiata i GM, Warszawa-Łódź związane z dawną FSO, obecnie własność ukraińskiego Avto-ZAZ, Poznań związany z fabryką Volkswagena i Wrocław związany z zakładem Toyoty w Wałbrzychu i zakładem Volkswagena w Polkowicach.

\section{Literatura}

Forbes 2006, Special Report. The Word`s 2000 largest Public Companies

Kamiński A., 2005, Europa Środkowo-Wschodnia w działalności koncernów międzynarodowych: na przyktadzie koncernów motoryzacyjnych, Wyd. Mater, Szczecin 
Menes E., 1998, Dylematy rozwoju motoryzacji indywidualnej w Polsce, Ośrodek Informacji Naukowej, Technicznej i Ekonomicznej, Zeszyty Naukowe, Instytut Transportu Samochodowego, Warszawa

Parysek J., Stryjakiewicz., 2000, Polish economy in transition: spatial perspectivies, Wydawnictwo Naukowe sc, Poznań

Piasecka K., 2001, Skala i struktura inwestycji zagranicznych w polskim przemyśle, Prace Komisji Geografii Przemysłu PTG, nr 2, pod red. Z. Zioło, Warszawa-Kraków

Oficjalna strona internetowa www.fiat.pl

\section{Influence of the FIAT concern on the shaping of the Polish automobile industry}

The change of economic system and switching to market economy, as well as opening the economy to international environment, significantly affected the changes in the national industry structure, including the restructuring of the automobile industry. In global economy, international corporations, among them the automobile companies, are carriers of the global economic increase, and the increase in economies of particular countries. On these bases, this paper presents an analysis of the influence of FIAT on the formation of the country's automobile industry.

The country's automobile industry is, to the greatest extent, connected with the Italian automobile concern FIAT. It has been present in Poland since 1932, when the first licence agreement was signed between the Polish government and FIAT; the agreement included building a car factory in Warsaw. In 1967 the Italian company launched the production of Fiat 125p in the Warsaw FSO factory in Żerań. In 1971, FIAT opened a very modern small-cars factory, FSM, in Bielsko-Biała and Tychy. In 1992, due to its serious situation, it was taken over by FIAT and transformed into three new companies, belonging to the FIAT group, which were: Fiat Auto Poland, Teksid, and Magneti-Marelli. FIAT also took over a number of smaller, chiefly state-owned firms, connected to it by corporational links, which used to be its suppliers. It also took over a number of enterprises which were not connected with automobile industry, e.g. the Bicycle Factory Apollo in Czechowice-Dziedzice, or the factory of lathes in BielskoBiała.

FIAT conducted restructuring of its factories (earlier FSM), privatized the supplier firms which were not connected directly with the car production, and sold the metallurgic enterprises in BielskoBiała and Skoczów. These firms were taken over in 1992, by Teksid, which belonged to the FIAT concern. After the foundry in Skoczów was taken over, its production profile was modified and adapted to the needs of the automobile industry.

The FIAT concern has strongly influenced the present form of the Polish automobile industry. This is visible in the fact that in the first years of the economic transformation, having taken over FSM factories, it sold the enterprises not connected with car production, and introduced remedial programmes in the remaining firms, thus significantly improving their efficiency and production quality. Restructuring led to production specialization in particular enterprises.

In 2005, FIAT employed 8812 workers in Poland. Nowadays the FIAT group is composed of 16 companies and 3 joint-venture enterprises. In the structure of the FIAT group in Poland, the most important is Fiat Auto Poland, specializing in car production, with 3531 employees, i.e. $40.1 \%$ of all the group's workers. Next is Fiat-GM Powertrain Polska, with 1356 employees, which makes 15.4\% of the group's employment. Both these enterprises are dominating in the group and concentrate $55.5 \%$ of all its employees. 
The FIAT factory in Bielsko-Biała has attracted about 32 foreign cooperating investors to Poland, including Teksid Aluminium, Teksid Iron Poland, Magneti-Marelli, Gestind, Delphi, TRW, and others. As a result of restructuring actions in the Polish automobile industry, currently there are four areas in the country in which automobile enterprises are located: Bielsko-Biała - Gliwice, Warszawa-Łódź, Poznań, and Wrocław. 